\title{
CLINICAL INVESTIGATION OF APPLICATION OF SEVOFLURANE AND MUSCLE RELAXANT TO FOREIGN BODY EXTRACTION IN RESPIRATORY TRACT OF CHILDREN
}

\author{
Y. Tong ${ }^{1}$, X. Zhang ${ }^{2}$, L. Yan ${ }^{2}$, R. Kuang ${ }^{2}$, X. Zhou ${ }^{2}$ \\ ${ }^{1}$ Anesthesia, ${ }^{2}$ Anesthesiology, Hunan Children's Hospital, Changsha, China
}

Objective: To compare the advantages and disadvantages of anesthesia by Cisatracurium, small dose Cisatracurium, sevoflurane and smaller dose Cisatracurium in the anesthesia of tracheobronchial foreign body extraction in children.

Methods: Sixty children aged from 5 months to 7 years who were performed tracheobronchial foreign body extraction were randomly allocated to three groups: group $C_{1}$ (Cisatracurium $0.1 \mathrm{mg} / \mathrm{kg}$ ), group $C_{2}$ (Cisatracurium $0.08 \mathrm{mg} / \mathrm{kg}$ ), group $\mathrm{C}_{3}$ (sevoflurane + Cisatracurium $0.06 \mathrm{mg} / \mathrm{kg}$ ). The time of operation and recovery, the number of body movement or breathe action 3 min after administration, the adverse reaction of airway (such as bucking, breath holding, laryngismus) were recorded.

Results: There is no significant difference of the operation time between the three groups, the time of recovery : $\mathrm{C}_{1}>\mathrm{C}_{2}>\mathrm{C}_{3}$, the patients of group $\mathrm{C}_{1}$, group $\mathrm{C}_{2}$ were well relaxant after administration, but there are $30 \%$ patients still had body movement or breathe action after administration. There is no adverse reaction in the three groups.

Conclusions: The application of sevoflurane and Cisatracurium in tracheobronchial foreign body extraction in children is safe. 